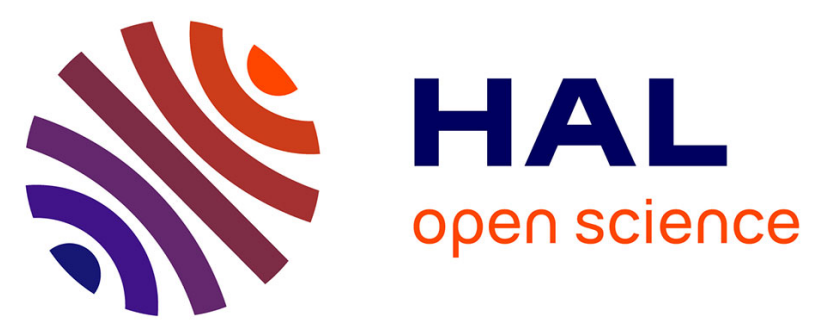

\title{
Food Structure Modulates the Bioavailability of Triglycerides and Vitamin D, and Partly That of Lutein: A Randomized Trial with a Crossover Design in Adults
}

Beatrice Gleize, Manon Hiolle, Nathalie Meunier, Bruno Pereira, Ruddy Richard, Isabelle Savary-Auzeloux, Caroline Buffière, Marie-agnès Peyron, Charlotte Halimi, Catherine Caris-Veyrat, et al.

\section{To cite this version:}

Beatrice Gleize, Manon Hiolle, Nathalie Meunier, Bruno Pereira, Ruddy Richard, et al.. Food Structure Modulates the Bioavailability of Triglycerides and Vitamin D, and Partly That of Lutein: A Randomized Trial with a Crossover Design in Adults. Molecular Nutrition and Food Research, 2020, pp.2000228. 10.1002/mnfr.202000228 . hal-02976032

\section{HAL Id: hal-02976032 \\ https://hal.inrae.fr/hal-02976032}

Submitted on 23 Oct 2020

HAL is a multi-disciplinary open access archive for the deposit and dissemination of scientific research documents, whether they are published or not. The documents may come from teaching and research institutions in France or abroad, or from public or private research centers.
L'archive ouverte pluridisciplinaire HAL, est destinée au dépôt et à la diffusion de documents scientifiques de niveau recherche, publiés ou non, émanant des établissements d'enseignement et de recherche français ou étrangers, des laboratoires publics ou privés.

\section{(ㅇ)(1) $\$$}

Distributed under a Creative Commons Attribution - NonCommercial - NoDerivatives 44.0 


\title{
Food Structure Modulates the Bioavailability of Triglycerides and Vitamin D, and Partly That of Lutein: A Randomized Trial with a Crossover Design in Adults
}

\author{
Béatrice Gleize, Manon Hiolle, Nathalie Meunier, Bruno Pereira, Ruddy Richard, \\ Isabelle Savary-Auzeloux, Caroline Buffière, Marie-Agnès Peyron, Charlotte Halimi, \\ Catherine Caris-Veyrat, Françoise Nau, and Emmanuelle Reboul**
}

Scope: The specific effect of the food matrix structure on fat-soluble micronutrient bioavailability is only partly understood. Evaluating fat-soluble micronutrient bioavailability after consumption of foods displaying similar composition but different structure is aimed at.

Methods and results: Twelve healthy subjects are enrolled in a randomized, open label, crossover postprandial trial. Four different model foods are tested: custard, pudding, sponge cake, and biscuit. Vitamin $\mathrm{D}_{3}$, lutein, and triglyceride chylomicron responses, evaluated as postprandial areas under the curve, are then assayed. Custard triglyceride response is higher than pudding and biscuit responses (up to $+122.7 \%, p<0.0001$ ). Sponge cake vitamin $D_{3}$ response is higher than biscuit response $(+26.6 \%, p=0.047)$. No difference between the model foods are observed regarding lutein responses. Triglyceride responses peak at $3 \mathrm{~h}$ for all conditions, while vitamin $D_{3}$ and lutein peaks are delayed by $1 \mathrm{~h}$ with the biscuit matrix compared to other model foods. Conclusion: Food structure can significantly impact on triglyceride and vitamin $D_{3}$ bioavailability in terms of absorbed amounts and/or maximum absorption time. The data highlight positive correlations between triglyceride, vitamin $D$, and lutein nutrient responses. These results are of particular interest to develop functional foods for population subgroups such as the elderly.

\section{Introduction}

Fat-soluble vitamins (i.e., vitamin A, D, E, and $\mathrm{K}$ ) and bioactive phytochemicals (i.e., carotenoids) play key roles in both development and healthy aging. Although less frequent than in developing countries, fat-soluble vitamin (principally vitamin $\mathrm{D}$ and E) sub-deficiencies and/ or insufficient intakes have also been described in Western countries. ${ }^{[1,2]}$ The link between these inadequacies and the increasing incidence of chronic diseases such as neurodegenerative, bone, or cardiovascular pathologies is now extensively investigated because many reports strongly suggest causative relationships..$^{[3,4]}$

The most frequent inadequacy concerns vitamin $\mathrm{D}_{3} \quad$ (cholecalciferol). ${ }^{[3]}$ This vitamin is involved in many functions including the optimal functioning of the musculoskeletal system. ${ }^{[5]}$ In most people, sun exposure is not sufficient to reach satisfactory vitamin D levels. ${ }^{[3]}$ A complementary dietary intake is thus necessary. Optimizing the bioavailability of vitamin $\mathrm{D}_{3}$ dietary intake would be of great interest. Another bioactive phytochemical of interest is the carotenoid lutein. This xanthophyll is not a "micronutrient" per se because

Dr. B. Gleize, Dr. C. Caris-Veyrat

INRAE

Avignon Université, UMR SQPOV

Avignon 84914, France

Dr. M. Hiolle, Prof. F. Nau

STLO, INRAE

AGROCAMPUS OUEST

Rennes 35042, France

Dr. N. Meunier, Prof. R. Richard

$\mathrm{CHU}$ Clermont-Ferrand

Centre de Recherche en Nutrition Humaine Auvergne

Clermont-Ferrand 63000, France

\author{
Dr. B. Pereira, Prof. R. Richard \\ $\mathrm{CHU}$ Clermont-Ferrand \\ $\mathrm{DRCl}$ \\ Clermont-Ferrand 63000, France \\ Dr. I. Savary-Auzeloux, C. Buffière, Dr. M.-A. Peyron \\ INRAE, Unité de Nutrition Humaine, UMR 1019 \\ University Clermont Auvergne \\ Clermont-Ferrand F-63000 France \\ C. Halimi, Dr. E. Reboul \\ Aix-Marseille Université \\ INRAE, INSERM, C2VN \\ Marseille, France \\ E-mail: Emmanuelle.Reboul@univ-amu.fr
}

The ORCID identification number(s) for the author(s) of this article can be found under https://doi.org/10.1002/mnfr.202000228

DOI: 10.1002/mnfr.202000228 
its essentiality has not been proven in humans yet. Nevertheless, lutein was shown to selectively accumulate in the retina ${ }^{[6,7]}$ where its presence has been negatively associated with the incidence of age-related macular degeneration, ${ }^{[8,9]}$ which is a major cause of visual impairment in elderly. Lutein beneficial effect is likely due to its ability to protect photoreceptors from blue light. ${ }^{[10-12]}$ Recent randomized, placebo-controlled clinical trials have confirmed these data as xanthophyll supplementation improves patient visual function and decreases the risk of progression to late age-related macular degeneration. ${ }^{[13]}$ Optimizing dietary lutein intake would thus be of great interest as well.

Over the past decades, many studies explored the factors modulating fat-soluble micronutrient absorption (see for review $\left.{ }^{[14,15]}\right)$. Indeed, even if these molecules are provided in sufficient amounts by the diet, their beneficial effects depend on their bioavailability, which can be affected by interactions with the matrix in which they are embedded.

The specific effect of food structure on the digestion of macronutrients such as proteins, ${ }^{[16]}$ lipids, ${ }^{[17]}$ or carbohydrates $^{[18]}$ has previously been explored, but studies on the effect of food structure on fat-soluble micronutrients remain scarce. In particular, there is no clear clinical data on fat-soluble vitamin release kinetics into the bloodstream after consuming foods with similar composition but different structures.

To fill this gap, we comprehensively compared both vitamin $\mathrm{D}_{3}$ (as a model of fat-soluble vitamin) and lutein (as a model of carotenoid) postprandial responses in healthy subjects, after the consumption of four model foods presenting similar nutrient composition but different structures, that is, custard, pudding, sponge cake, and biscuit.

\section{Experimental Section}

\subsection{Subject Number and Characteristics}

The main objective of the study was to highlight the link between food structure and fat-soluble micronutrient postprandial responses. The primary outcomes were thus lutein and vitamin $\mathrm{D}_{3}$ postprandial concentrations in chylomicrons. Previous works reported that 10-20 subjects would be relevant to perform kinetics studies having a satisfactory statistical power greater than $80 \% .{ }^{[19,20]}$ Twelve healthy, non-obese, non-smoking men were thus recruited for the study by the Unité d'Exploration Nutritionnelle (Centre de Recherche en Nutrition Humaine Auvergne, Clermont-Ferrand, France). Only men were enrolled to decrease interindividual variability in the observed responses. Subjects had no history of chronic disease, hyperlipidemia, or hyperglycemia and they were not taking any medication known to affect vitamin $\mathrm{D}_{3}$ or lipid metabolism 3 months before the study or during the study period. They had to have at least 28 teeth, stable Angle Class I occlusion, no jaw pain, no current dental treatment, and no orthodontic procedure in the 3 years preceding the study. Subjects' baseline characteristics are reported in Table 1. Plasma glucose was evaluated at using hexokinaseglucose-6-phosphate dehydrogenase method. Hemoglobin was assayed by a quantitative and qualitative automated method (spectrometry, impedancemetry, cytofluorimetry); completed, if necessary, by cytological analysis and microscopic control. 25-hydroxyvitamin D status was evaluated with a chemilumines-
Table 1. Baseline characteristics of healthy men.

\begin{tabular}{lc}
\hline Parameter & Value \\
\hline Age $[\mathrm{y}]$ & $22.6 \pm 0.4$ \\
Weight $[\mathrm{kg}]$ & $71.2 \pm 1.4$ \\
BMI $\left[\mathrm{kg} \mathrm{m}^{-2}\right]$ & $22.1 \pm 0.4$ \\
Glucose $\left[\mathrm{mmol} \mathrm{L}^{-1}\right]$ & $4.22 \pm 0.12$ \\
Hemoglobin $\left[\mathrm{g} \mathrm{dL}^{-1}\right]$ & $15.6 \pm 0.3$ \\
25-Hydroxyvitamin D $\left[\mathrm{\mu g} \mathrm{L}^{-1}\right]$ & $22.7 \pm 1.1$ \\
\hline
\end{tabular}

cence immunological assay. Subjects were asked to avoid foods rich in the studied micronutrients for 48 -h meals preceding each kinetics (see Table S1, Supporting Information). All subjects consumed each of the four model foods in a randomized order during four sessions (random Latin-square design). These sessions were separated by at least 3 weeks of wash-out because of the model foods provided higher amounts of vitamin $\mathrm{D}_{3}$ and lutein than usual foods. The study was approved by the regional committee on human experimentation (IDRCB 2017-A01996-47, France): Clinical trial registry NCT03413267 (ClinicalTrials.gov). Procedures followed were in accordance with the Declaration of Helsinki of 1975 as revised in 1983. Objectives and requirements of the study were fully explained to all participants before beginning the study, and written informed consent was obtained from each subject. Participant flow chart is presented in Figure 1.

\subsection{Model Food Preparation}

The model foods were formulated with wheat flour (Francine T45, Grands Moulins de Paris, Ivry Sur Seine, France), extruded pea flour (Sativa 32/100, Sotexpro, Bermericourt, France), powdered sugar (Saint-Louis Sucre, Paris, France), sunflower oil (Lesieur, Asnières-sur-Seine, France), standard pasteurized egg yolk and granulated pasteurized egg white powders (Liot, Pleumartin, France), and sterilized water. Powdered vitamin $\mathrm{D}_{3}$ was supplied by Nutrilo GmbH (ref 05-052, Cuxhaven, Germany). Lutein was provided from Diet Horizon (ref 2779, Bordeaux, France) as capsules containing a suspension of about $20 \mathrm{mg}$ lutein in sunflower oil; a homogeneous dispersion of lutein was produced from these capsules and its concentration was determined by spectrophotometry at $445 \mathrm{~nm}$ using lutein molecular extinction coefficient.

Four model foods (one liquid and three solids) enriched in both vitamin $\mathrm{D}_{3}$ and lutein were produced according to the flowcharts described in Figure S1, Supporting Information. Model food composition is presented in Table 2. Kneading, whisking, mixing steps, and heat treatment for custard were operated with a kitchen robot Thermomix TM5 (Vorwerk, Wuppertal, Germany). Cooking of biscuit, sponge cake, and pudding was operated with a semi-professional convection oven (De Dietrich, Niederbronn-Les-Bains, France). On dry matter, the model food recipes were all composed of $17 \%$ proteins, $52 \%$ carbohydrates, and $30 \%$ lipids. Custard was prepared as a packed-powder that was rehydrated and heated before use. Pudding, sponge cake, and biscuit were stored at $-20^{\circ} \mathrm{C}$ until use and then defrosted at room temperature. 


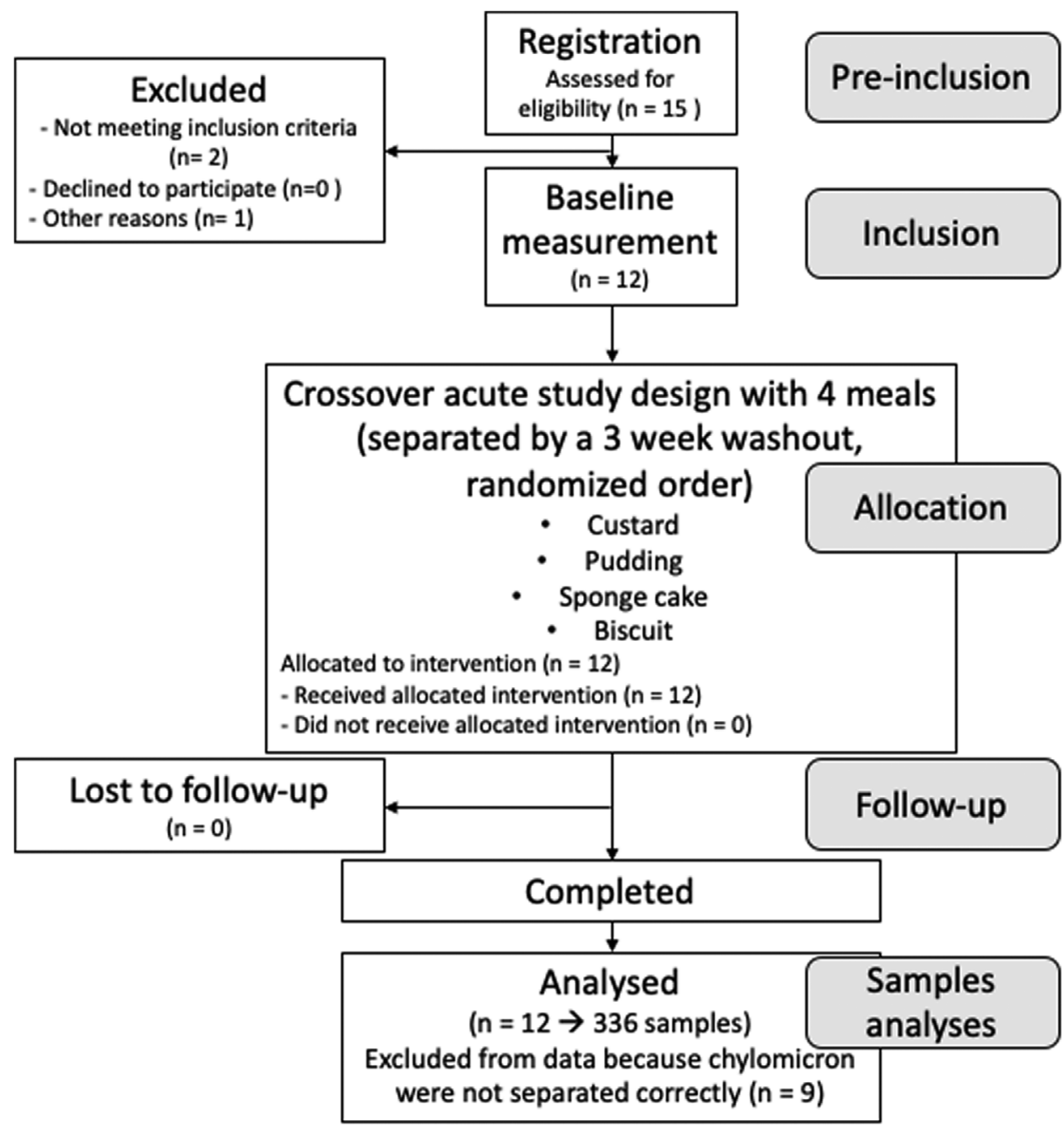

Figure 1. Participant flow chart.

Table 2. Model food recipes and nutritional composition.

\begin{tabular}{|c|c|c|c|c|c|}
\hline & & Custard & Pudding & Sponge cake & Biscuit \\
\hline \multirow[t]{7}{*}{ Recipes [g per portion] } & Wheat flour & 10.2 & 10.2 & 10.2 & 10.2 \\
\hline & Pea flour & 10.2 & 10.2 & 10.2 & 10.2 \\
\hline & Egg white powder & 54.2 & 54.2 & 54.2 & 54.2 \\
\hline & Egg yolk powder & 30.5 & 30.5 & 30.5 & 30.5 \\
\hline & Sugar & 10.2 & 10.2 & 10.2 & 10.2 \\
\hline & Sunflower oil & 20.3 & 20.3 & 20.3 & 20.3 \\
\hline & Water & 376.3 & 169.5 & 118.7 & 17.0 \\
\hline \multirow{3}{*}{$\begin{array}{l}\text { Macronutrient composition after preparation [g per } \\
\text { portion] }\end{array}$} & Proteins & $21.49 \pm 0.09$ & $22.24 \pm 0.20$ & $20.64 \pm 0.27$ & $21.06 \pm 0.29$ \\
\hline & Lipids & $39.06 \pm 0.94$ & $40.33 \pm 0.66$ & $35.75 \pm 1.44$ & $35.83 \pm 0.53$ \\
\hline & Carbohydrates & $68.13 \pm 0.88$ & $66.47 \pm 0.44$ & $72.74 \pm 1.66$ & $72.06 \pm 0.82$ \\
\hline \multirow{2}{*}{$\begin{array}{l}\text { Lutein and vitamin } D_{3} \text { content after preparation [mg per } \\
\text { portion] }\end{array}$} & Lutein & $22.70 \pm 2.77$ & $20.30 \pm 1.66$ & $17.34 \pm 0.98$ & $19.49 \pm 1.19$ \\
\hline & Vitamin $D_{3}$ & $1.98 \pm 0.40$ & $1.20 \pm 0.09$ & $1.06 \pm 0.04$ & $1.27 \pm 0.14$ \\
\hline
\end{tabular}




\subsection{Confocal Microscopy and Image Analysis of the Model Foods}

Model food slices $(300 \mu \mathrm{m})$ were cut either on a cryotome at $-20^{\circ} \mathrm{C}$ for biscuit, or on a microtome for sponge cake and pudding, and transferred onto glass slides. Fluorescent probes (Fast Green and Red Nile) were applied to the slides and let to diffuse for $10 \mathrm{~min}$. The two probes were mixed with custard before incubation for $10 \mathrm{~min}$, and the mixture was applied directly on slides. Slides were covered with a spacer and a cover slide and were imaged using a LSM880 inverted confocal microscope (Carl Zeiss AG, Oberkochen, Germany). Images were analyzed using Image J software. The results obtained were then analyzed as described previously ${ }^{[21]}$ by fitting the cumulative percentage of lipid droplets area to the Rosin-Rammler equation. ${ }^{[22]}$ This enabled, using linear regression techniques, to extract two parameters to describe the distribution curves of the lipid droplet sizes, namely $\times 50$, which is the median particle area $\left(\mu \mathrm{m}^{2}\right)$ and $b$, a dimensionless constant, which represent the broadness of the distribution.

\subsection{Postprandial Experiments}

Because it has been shown that season is an important prediction factor for vitamin $\mathrm{D}_{3}$ response variation, ${ }^{[23]}$ the postprandial experiments were performed in winter, and more precisely between November 2017 and March 2018. Subjects were asked to eat a standardized dinner between $7 \mathrm{pm}$ and $8 \mathrm{pm}$ the day before the postprandial experiment and to abstain from any food or beverage consumption afterward-with the exception of water. After an overnight fast, subjects arrived at the Unité d'Exploration Nutritionnelle and a baseline blood sample was taken. Subjects then consumed the model food together with $200 \mathrm{~mL}$ of mineral water. Subjects were asked to consume the model food within $15 \mathrm{~min}$ (to diminish the variability due to different rates of intake and, thus, gastric emptying). No other food was permitted over the following $8 \mathrm{~h}$. However, subjects were asked to drink $100 \mathrm{~mL}$ water every $2 \mathrm{~h}$ (up to $500 \mathrm{~mL}$ ). Additional blood samples were taken at 2, 3, 4, 5, 6, and $8 \mathrm{~h}$ after meal consumption. Blood was collected in heparin-lithium tubes that were immediately placed on ice and covered with aluminum foil to avoid light exposure, then centrifuged at $1500 \times \mathrm{g}$ for $10 \mathrm{~min}$ at $4{ }^{\circ} \mathrm{C}$.

\subsection{Chylomicron Preparation}

Chylomicrons were prepared from plasma samples as previously described. ${ }^{[2]}$ Immediately after recovery, chylomicrons were stored at $-80^{\circ} \mathrm{C}$ until analysis.

\subsection{Lipid Analysis}

Cholesterol, phospholipids, and triglycerides (TG) in chylomicrons were analyzed as previously described. ${ }^{[25]}$

\subsection{Model Food Lutein and Vitamin $D_{3}$ Extraction and Analysis}

Model foods ( $\approx 100 \mathrm{mg}$ ) were homogenized in $800 \mu \mathrm{L}$ of saturated $\mathrm{NaCl}$ solution with 1-mm-diameter ceramic balls in $2 \mathrm{~mL}$ Eppendorf tubes using a FastPrep-24 5G (MP Biomedicals, Illkirch, France).
Lutein was extracted following the Bligh and Dyer method ${ }^{[26]}$ and using apo-8'-carotenal as an internal standard. The extract was evaporated to dry under argon and dissolved in $600 \mu \mathrm{L}$ of methanol/dichloromethane $(65 / 35, \mathrm{v} / \mathrm{v})$. A final volume of $10 \mu \mathrm{L}$ was used for HPLC analysis.

Vitamin $\mathrm{D}_{3}$ was extracted by adding 1 volume of ethanol, which also contained ergocalciferol (vitamin $\mathrm{D}_{2}$ ) as an internal standard, and vortexing for $30 \mathrm{~s}$. After adding 2 volumes of hexane, the mixture was vortexed for $10 \mathrm{~min}$ and centrifuged at $500 \times \mathrm{g}$ for $10 \mathrm{~min}$ at $4{ }^{\circ} \mathrm{C}$. The upper phase (containing the different vitamin $\mathrm{D}$ forms) was collected and the sample was extracted a second time with hexane following the same procedure. The hexane phases were pooled and completely evaporated under nitrogen gas. The dried residue was dissolved in $200 \mu \mathrm{L}$ methanol/dichloromethane $(65 / 35, v / v)$ and a final volume of $100 \mu \mathrm{L}$ was used for HPLC analysis.

Reverse-phase HPLC was then performed as previously described for lutein ${ }^{[27]}$ and vitamin $\mathrm{D}_{3}{ }^{[28]}$ quantification.

\subsection{Chylomicron Lutein and Vitamin $D_{3}$ Extraction and Analysis}

Lutein and vitamin $\mathrm{D}_{3}$ from chylomicron samples were extracted by the methods previously described. ${ }^{[27,28]}$ The whole extracts were evaporated to dryness under argon and dissolved in $100 \mu \mathrm{L}$ of methanol/dichloromethane $(65 / 35, v / v)$. A final volume of $90 \mu \mathrm{L}$ was used for reverse-phase HPLC analysis. Lutein was detected at $445 \mathrm{~nm}$ and was identified by retention time and spectral analysis (300-500 $\mathrm{nm})$ compared with pure lutein standard. Vitamin $\mathrm{D}_{3}$ was detected at $265 \mathrm{~nm}$ and was identified by retention time and spectral analysis (200-400 nm) compared with pure vitamin $\mathrm{D}_{3}$ standard. The two compounds were quantified by comparing peak area with standard calibration curves and were corrected by extraction efficiency based on recovery of internal standard.

\subsection{Calculation and Statistical Analysis}

The trapezoidal approximation method was used to calculate area under the curve (AUC) of the postprandial plasma chylomicron TG, lutein, and vitamin $\mathrm{D}_{3}$ concentration over $8 \mathrm{~h}$, henceforth referred to as TG, lutein, or vitamin $\mathrm{D}_{3}$ response. Lutein and vitamin $D_{3}$ responses were corrected for ingested lutein and vitamin $\mathrm{D}_{3}$. Uncorrected curves are presented in Figures S2 and S3, Supporting Information. Coefficient of variation (CV) of TG, lutein, and vitamin $\mathrm{D}_{3}$ responses were calculated as the ratio of standard deviation compared to the mean.

All tests were two-sided, with a type I error set at 0.05 . Continuous data were expressed as mean \pm standard error of mean. The assumption of normality was assessed by using the Shapiro-Wilk test. Random-effects models for repeated data were performed to compare the four ingested matrices considering the following fixed effects: i) matrix and for longitudinal analyses, time-point evaluation and time $\mathrm{x}$ matrix interaction, and ii) taking into account between and within participant variability (subject as random-effect). Furthermore, due to cross-over randomized design, period, matrix order, and carry-over were also considered as covariates. When appropriate, a Sidak's type I error correction 

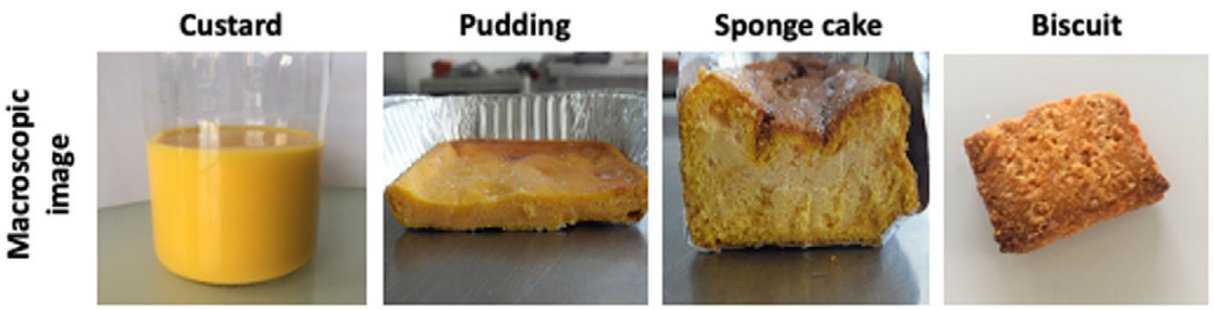

A
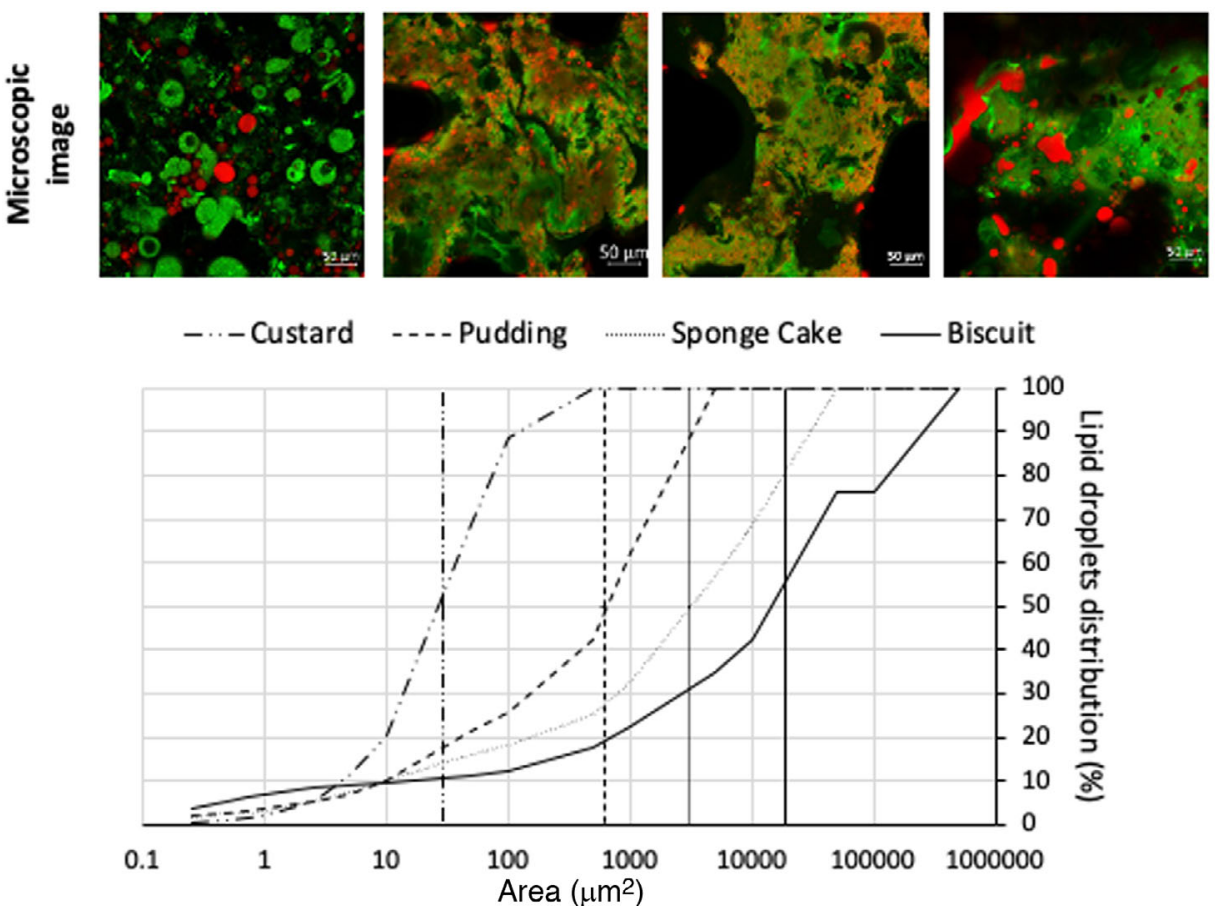

Figure 2. Model food characteristics. A) Macroscopic and microscopic images of model foods. Confocal images are at magnification $\times 20$ and lipids appear in red and proteins in green. B) Lipid size distribution of model foods. Vertical lines correspond to $\times 50$, the median particle area of each distribution $\left(\mu \mathrm{m}^{2}\right)$.

was applied to perform multiple comparisons. The normality of residuals from these models was studied using the ShapiroWilk test. When appropriate, a logarithmic transformation was proposed to achieve the normality of dependent outcome.

Statistical dependence between two variables was assessed by Pearson's correlation coefficient $(r)$. Statistical analyses were performed using Stata software (version13, StataCorp, College Station, USA) and R software. For all tests, a $p$-value $<0.05$ was considered significant.

\section{Results}

\subsection{Model Food Characteristics}

The differences in the production process and the water content resulted in four strongly different model foods in terms of macroscopic aspect (Figure 2A). The biscuit was a very dry and brittle product. The sponge cake was a soft and dry gel with a honeycomb structure, while the pudding was a wet and compact gel. Finally, the custard was a thick liquid.

Confocal microscopy images of the four model foods are presented in Figure 2A. A continuous protein network was observed in biscuit, sponge cake, and pudding, as suggested by the uniform green background. In regard to the custard, protein aggregation was suspected because of the small green particles of about $50 \mu \mathrm{m}$. With regards to the lipid phase, fat droplets had different shapes depending on the model foods: fat globules could be seen in the custard versus fat "flakes" (i.e., large spots) in the biscuit. Both droplets and flakes were characterized by their area. Lipid droplets appeared bigger in custard and biscuit compared to sponge cake and pudding, in which lipids were more diffused. The distribution curves of lipid droplets area confirmed the bigger size of lipid droplets in the biscuit (Figure 2B): this matrix presented the higher median droplet size, around $18000 \mu \mathrm{m}$. However, the median droplet size measured for custard was surprisingly the lowest amongst the four model foods (median size around $30 \mu \mathrm{m}$ ). Despite large lipid droplets were observed on the confocal images, the custard was actually mainly composed of very small fat droplets that could not be observed on the image presented in Figure 2A because of their reduced size. Sponge cake and pudding presented intermediate median area of lipid droplets, around 3000 and $600 \mu \mathrm{m}$, respectively. 

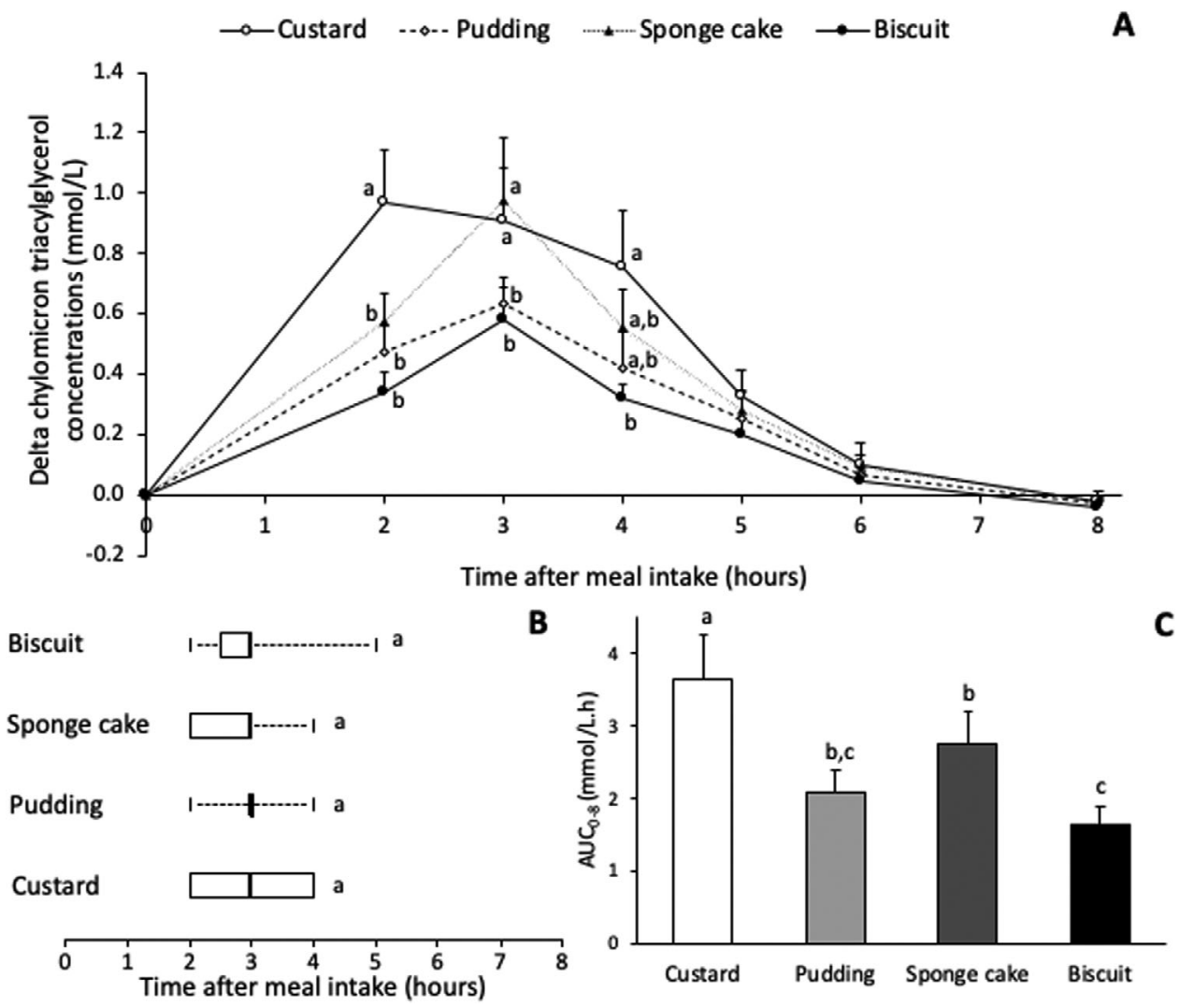

Figure 3. Chylomicron triglyceride (TG) responses. A) Baseline-adjusted chylomicron TG concentration over $8 \mathrm{~h}$ after the consumption of model foods. Data are means $\pm \operatorname{SEM}(n=12)$. At each time, a different letter indicates a significant difference $(p<0.05)$. B) Time of maximum TG concentration after the consumption of model foods. Vertical bars represent medians; boxes represent 25 th-75th percentiles and whiskers indicate the maximal and the minimal values. A different letter indicates a significant difference $(p<0.05)$. C) Postprandial chylomicron TC responses $(0-8 \mathrm{~h} \mathrm{AUC)}$ after the consumption of model foods. Data are means $\pm \operatorname{SEM}(n=12)$. A different letter indicates a significant difference $(p<0.05)$.

Lastly, for the distribution spread measured by the $b$ constant, custard was found to have the narrowest size distribution (as indicated by the highest $b$ value, 1.08), followed by pudding (0.46), sponge cake $(0.38)$, and then biscuit $(0.25)$.

\subsection{Chylomicron TG Response to the Four Different Model Foods}

The mean TG concentration after consumption of the different model foods is shown in Figure 3A. All subjects had extremely low chylomicron TG concentrations $\left(<0.109 \pm 0.064 \mathrm{mmol} \mathrm{L}^{-1}\right)$ at $\mathrm{T} 0$, which confirmed that they were at fast at the beginning of the experiment.

The maximal chylomicron TG concentrations after custard, pudding, sponge cake, and biscuit consumption were obtained $3 \mathrm{~h}$ after meal intake (Figure $3 \mathrm{~B}$ ). The chylomicron TG responses (i.e., $0-8 \mathrm{~h}$ AUC) ranged as follows: $3.63 \pm 0.62,2.77 \pm 0.44$, $2.07 \pm 0.33$, and $1.63 \pm 0.25 \mathrm{mmol} \mathrm{L}^{-1}$ per hour for custard, sponge cake, pudding, and biscuit, respectively. Custard TG response was significantly higher than pudding and biscuit responses $(+75.3 \%$ and $+123 \%$, respectively, $p<0.0001)$. Sponge cake TG response was significantly higher than biscuit response $(+69.7 \%, p=0.002)$ (Figure $3 \mathrm{C}$ ). The CV of the TG response was $64.8 \%$ and the ratio between the highest and the lowest responder was $\approx 16$.

\subsection{Chylomicron Vitamin $D_{3}$ Response to the Four Different Model Foods}

The mean vitamin $\mathrm{D}_{3}$ concentration after consumption of the different model foods is shown in Figure 4A and in Figure S2, Supporting Information. Ten out of the 12 subjects had vitamin $D_{3}$ concentrations below our limit of detection in their fasting chylomicron fraction, and the remaining two subjects had extremely low vitamin $\mathrm{D}_{3}$ fasting concentrations on one experimental day $\left(0.265 \pm 0.073 \mathrm{nmol} \mathrm{L}^{-1}\right)$.

The maximal chylomicron vitamin $\mathrm{D}_{3}$ concentrations were obtained $3 \mathrm{~h}$ after custard, pudding, sponge cake consumptions and $4 \mathrm{~h}$ after biscuit consumption (Figure 4B). The chylomicron vitamin $D_{3}$ responses ranged as follows: $24.29 \pm 3.31$, $23.19 \pm 2.83,21.98 \pm 3.08$, and $19.18 \pm 1.69 \mathrm{nmol} \mathrm{L}{ }^{-1}$ per hour for sponge cake, pudding, custard, and biscuit, respectively. Sponge cake vitamin $\mathrm{D}_{3}$ response was significantly higher than biscuit response $(+26.6 \%, p=0.047$; Figure $4 \mathrm{C})$. The $\mathrm{CV}$ of the vitamin $\mathrm{D}_{3}$ response was $43.2 \%$ and the ratio between the highest and the lowest responder was $\approx 7$. 

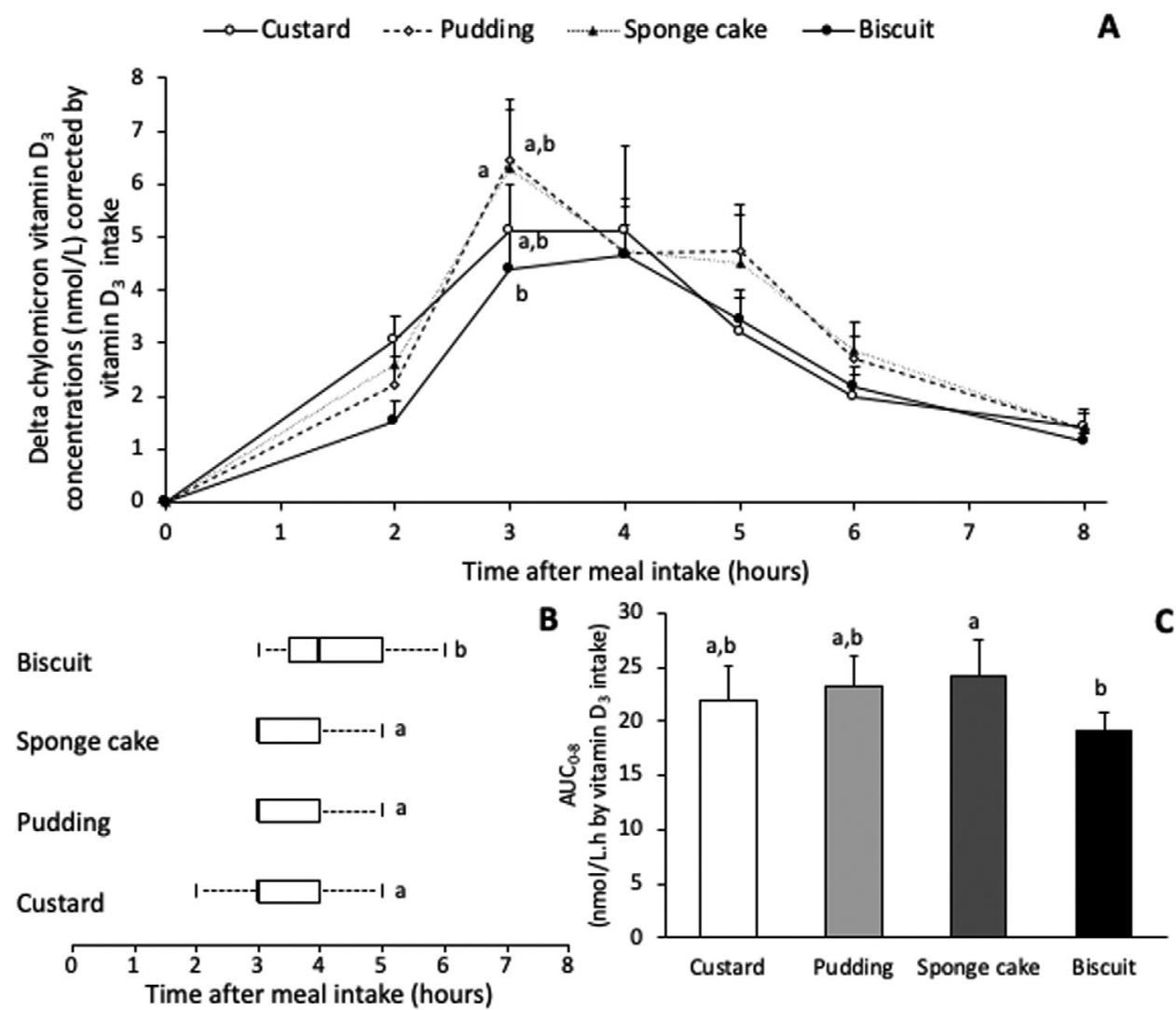

Figure 4. Chylomicron vitamin $D_{3}$ responses. A) Baseline-adjusted chylomicron vitamin $D_{3}$ concentration over $8 \mathrm{~h}$ after the consumption of model foods corrected by vitamin $\mathrm{D}_{3}$ intake. Data are means $\pm \operatorname{SEM}(n=12)$. At each time, a different letter indicates a significant difference $(p<0.05)$. B) Time of maximum vitamin $D_{3}$ concentration after the consumption of model foods. Vertical bars represent medians; boxes represent 25th-75th percentiles and whiskers indicate the maximal and the minimal values. A different letter indicates a significant difference $(p<0.05)$. C) Postprandial chylomicron vitamin $\mathrm{D}_{3}$ responses (0-8 h AUC) after the consumption of model foods corrected by vitamin $D_{3}$ intake. Data are means \pm SEM $(n=12)$. A different letter indicates a significant difference $(p<0.05)$.

Considering all model foods, the vitamin $\mathrm{D}_{3}$ response correlated positively with chylomicron TG response (Pearson's $r=$ $0.496, p=0.0003$ ). When model foods were considered separately, the relationship between vitamin $\mathrm{D}_{3}$ and TG responses was still significant for sponge cake (Pearson's $r=0.740, p=$ 0.006; Table 3).

\subsection{Chylomicron Lutein Response to the Four Different Model Foods}

The mean lutein concentration after consumption of the different model foods is shown in Figure 5A and in Figure S3, Supporting Information. Subjects had low fasting lutein concentrations in the chylomicron fraction $\left(<6.419 \pm 3.974 \mathrm{nmol} \mathrm{L}^{-1}\right)$.

The maximal chylomicron lutein concentrations after custard, pudding, sponge cake, and biscuit consumption were obtained $3 \mathrm{~h}, 3 \mathrm{~h} 30 \mathrm{~min}, 3 \mathrm{~h}$, and $4 \mathrm{~h}$ after meal intake, respectively (Figure 5B). The chylomicron lutein responses ranged as follows: $125.63 \pm 25.25,108.90 \pm 26.45$, $96.63 \pm 19.20$, and $76.08 \pm 15.72 \mathrm{nmol} \mathrm{L}^{-1}$ per hour for sponge cake, custard, biscuit, and pudding, respectively. Lutein response was not significantly different depending on the model food (Figure 5C). The CV of the lutein response was $74.9 \%$ and the ratio between the highest and the lowest responder was $\approx 69$.

Considering all model foods, the lutein response correlated positively with the chylomicron TG response (Pearson's $r=$ $0.324, p=0.025$ ) and the chylomicron vitamin $\mathrm{D}_{3}$ response (Pearson's $r=0.619, p<0.0001$ ). When model foods were considered separately, the positive relationship between lutein and TG responses was still significant in the case of pudding (Pearson's $r=0.607, p=0.038$ ), and the relationship between vitamin $\mathrm{D}_{3}$ and lutein responses was still significant for custard and pudding (Pearson's $r=0.877, p=0.0002$ and Pearson's $r=$ $0.650, p=0.022$, respectively; Table 3 ).

\section{Discussion}

In order to assess the bioavailability of lutein and vitamin $\mathrm{D}_{3}$, we measured the postprandial chylomicron lutein and vitamin $\mathrm{D}_{3}$ responses after consumption of four different model foods. This approach is commonly used for experimental assessment of both vitamin $\mathrm{D}_{3}{ }^{[28]}$ and carotenoid ${ }^{[29,30]}$ absorption and bioavailability, as chylomicrons mostly carry fat-soluble components from intestinal origin. Only men were enrolled in the study. One of the reasons for choosing groups of the same sex lies in fact that 


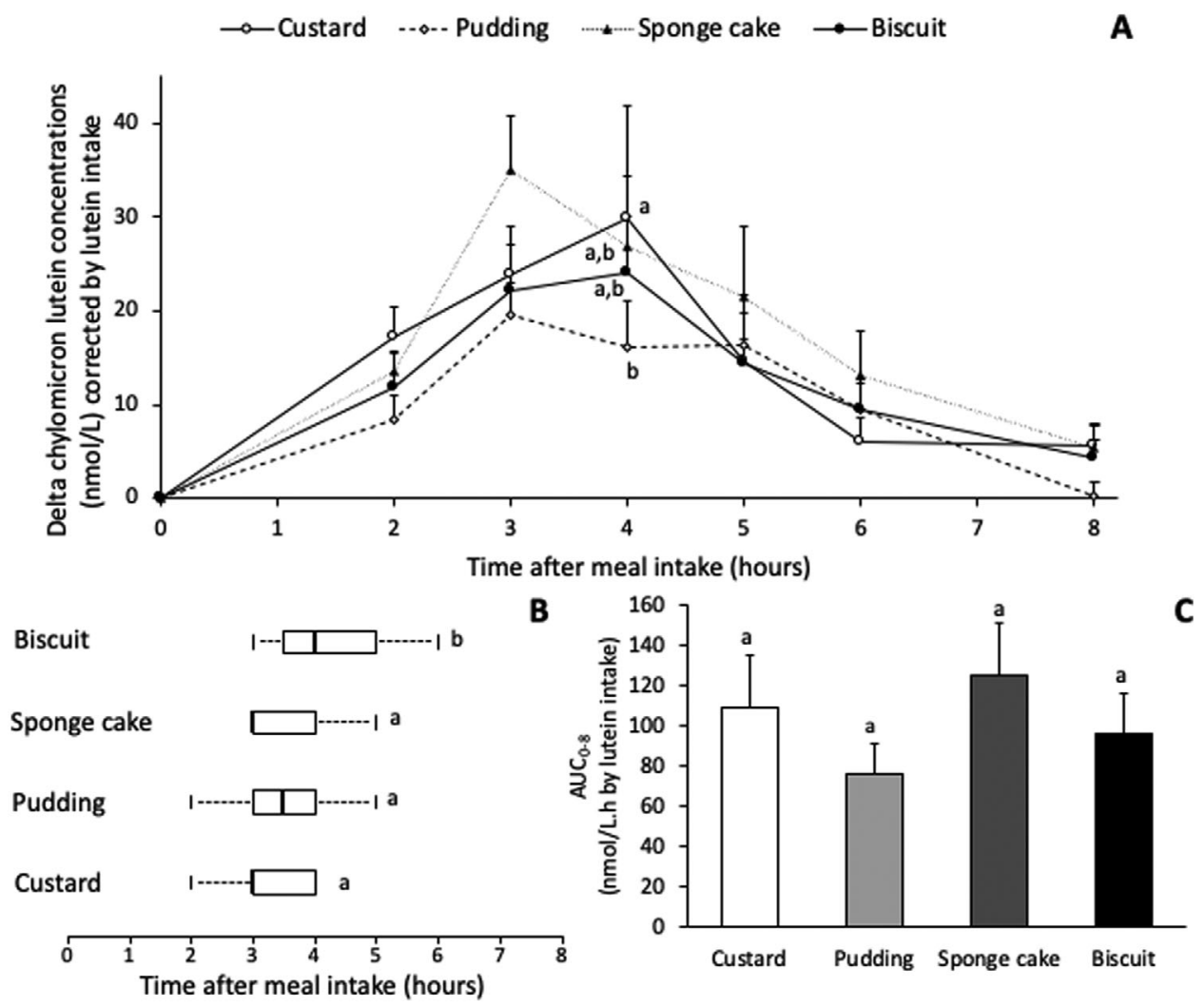

Figure 5. Chylomicron lutein responses. A) Baseline-adjusted chylomicron lutein concentration over $8 \mathrm{~h}$ after the consumption of model foods corrected by lutein intake. Data are means $\pm \operatorname{SEM}(n=12)$. At each time, a different letter indicates a significant difference $(p<0.05)$. B) Time of maximum lutein concentration after the consumption of model foods. Vertical bars represent medians; boxes represent 25th-75th percentiles and whiskers indicate the maximal and the minimal values. A different letter indicates a significant difference $(p<0.05)$. C) Postprandial chylomicron lutein responses $(0-8 \mathrm{~h}$ AUC) after the consumption of model foods corrected by lutein intake. Data are means \pm SEM $(n=12)$. A different letter indicates a significant difference $(p<0.05)$.

it may decrease the variability of responses between individuals. This is particularly true in postprandial studies providing a lipid challenge because lipid or lipid phytochemical responses are often lower in women than men due to a more efficient chylomicron-remnant clearance ${ }^{[31]}$ in relation with visceral adipose tissue accumulation. ${ }^{[32]}$

The food matrix has long been considered as a key factor modulating the absorption of fat-soluble micronutrients/phytomicroconstituents. Most of the studies performed so far simultaneously explored the effects of both food composition and food structure on fat-soluble micronutrient bioavailability. Indeed, in vitro, both carotenoid transfer from plant matrix to mixed micelles and carotenoid absorption significantly vary from one plant matrix to another. ${ }^{[3]]}$ This effect was also observed in vivo as broccoli and green peas were more effective sources of lutein than spinach in humans. ${ }^{[34]}$ This food matrix effect is less clear for vitamin $\mathrm{D}_{3} \cdot{ }^{[35]} \mathrm{A}$ food matrix containing fat such as cheese did not increase vitamin $\mathrm{D}_{3}$ bioavailability compared to a supplement in water in 8 healthy adults. ${ }^{[36]}$ Similarly, vitamin $\mathrm{D}_{3}$ bioavailability remained unaffected by a mushroom matrix compared to a supplement in 30 healthy adults ${ }^{[37]}$ In contrast, specific food components such as fatty acids ${ }^{[38]}$ or phytosterols ${ }^{[39]}$ were shown to modulate lutein bioavailability in humans. Similarly vitamin $\mathrm{D}_{3}$ absorption was modulated in vitro or in rodents by fatty acids and phytosterols, as well as proteins ${ }^{[40]}$ (see, for review, ref. [15]).

Besides, the effect of food processing on fat-soluble micronutrients bioavailability was specifically investigated. Although food processing leads to a partial degradation of vitamins and phytochemicals due to thermal and oxidative conditions, it also largely promotes matrix disruption. This disruption can balance the negative effect of micronutrient degradation by increasing micronutrient intestinal absorption. This effect is particularly important for carotenoids. Data obtained in humans highlighted that the consumption of $300 \mathrm{~g}$ per day of chopped spinach during 4 days improved lutein response compared to the consumption of whole

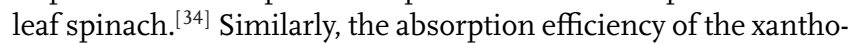
phyll $\beta$-cryptoxanthin was 1.8 -fold higher from orange juice than from fresh oranges ${ }^{[41]}$ By contrast, another clinical trial in which subjects received, for 3 weeks, spinach products including whole leaf spinach with an almost intact food matrix, minced spinach with a partially disrupted matrix, and enzymatically liquefied spinach, evidenced no effect of food matrix on lutein response. ${ }^{[42]}$ These discrepancies can be due to the fact that i) the sources of spinach used were not the same in the different studies, and ii) food processing can affect several aspects of the food matrix, including its composition and its structure, in a manner that highly depends on processing parameters. 
Table 3. Statistical dependence between TG, vitamin $D_{3}$, and lutein chylomicron responses according to model food.

\begin{tabular}{|c|c|c|}
\hline & $r$ & $p$-Value \\
\hline \multicolumn{3}{|l|}{ All model foods } \\
\hline Vitamin $D_{3}$ versus $T G$ responses & 0.4965 & $p=0.0003^{b)}$ \\
\hline Lutein versus TC responses & 0.3239 & $p=0.0247^{\mathrm{a})}$ \\
\hline Vitamin $D_{3}$ versus lutein responses & 0.6191 & $p<0.0001^{b)}$ \\
\hline \multicolumn{3}{|l|}{ Custard } \\
\hline Vitamin $\mathrm{D}_{3}$ versus TG responses & 0.4396 & $p=0.1527$ \\
\hline Lutein versus TG responses & 0.2605 & $p=0.4135$ \\
\hline Vitamin $D_{3}$ versus lutein responses & 0.8768 & $p=0.0002^{b)}$ \\
\hline \multicolumn{3}{|l|}{ Pudding } \\
\hline Vitamin $D_{3}$ versus TG responses & 0.5252 & $p=0.079$ \\
\hline Lutein versus TG responses & 0.6075 & $\left.p=0.036^{a}\right)$ \\
\hline Vitamin $D_{3}$ versus lutein responses & 0.6501 & $p=0.022^{\mathrm{a})}$ \\
\hline \multicolumn{3}{|l|}{ Sponge cake } \\
\hline Vitamin $D_{3}$ versus TC responses & 0.7404 & $p=0.006^{a)}$ \\
\hline Lutein versus TC responses & 0.4362 & $p=0.156$ \\
\hline Vitamin $D_{3}$ versus lutein responses & 0.4816 & $p=0.113$ \\
\hline \multicolumn{3}{|l|}{ Biscuit } \\
\hline Vitamin $D_{3}$ versus $T G$ responses & 0.3551 & $p=0.257$ \\
\hline Lutein versus TG responses & -0.0403 & $p=0.901$ \\
\hline Vitamin $D_{3}$ versus lutein responses & 0.5206 & $p=0.083$ \\
\hline
\end{tabular}

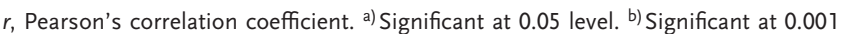
level.

To specifically study the effect of food matrix structure on micronutrient postprandial response, we designed four model foods corresponding to real foods (i.e., biscuit, sponge cake, pudding, and custard). These model foods were prepared with the same ingredients but displayed contrasted microstructures and macrostructures. The four different model food recipes only differed in their water content. As water was shown to have a minor effect on gastric emptying, ${ }^{[43]}$ this should not have impacted nutrient digestion. Nutrients were assessed in the final products to check the effect of processing. In particular, moderate differences in terms of lipid contents were observed after baking with a maximal difference of $11 \%$ was observed between pudding and sponge cake, which contained $40.3 \pm 0.7$ and $35.8 \pm 1.4 \mathrm{~g}$ of fat per portion, respectively. This is likely due to lipid leaching at high temperature. However, a previous study performed in healthy volunteers showed that no difference was observed for TG postprandial responses after the ingestion of meals containing 30 , 40 , or $50 \mathrm{~g}$ of fat. ${ }^{[44]}$ Consequently, the differences observed in our study in terms of (micro)nutrient responses, which were corrected by the amounts of ingested micronutrients, are expected to be mainly due to model food structure.

The CV for TG (64.8\%), vitamin $\mathrm{D}_{3}(43.2 \%)$, and lutein $(74.9 \%)$ responses are consistent with those obtained in previous studies. In a previous trial performed in 39 healthy men, the $\mathrm{CV}$ of responses in chylomicrons were $49 \%$ for $\mathrm{TG}^{\left[{ }^{[45]} 47 \% \text { for vita- }\right.}$ $\min \mathrm{D}_{3},{ }^{[28]}$ and $75 \%$ for lutein. ${ }^{[29]}$ respectively. This confirms the very high interindividual variability regarding the absorption efficiency of fat-soluble compounds.
Interestingly, when considering all model foods, vitamin $\mathrm{D}_{3}$ response was positively and significantly correlated with chylomicron TG response (Table 3). This is consistent with previous published data. ${ }^{[28]}$ Lutein response was also significantly and positively correlated with chylomicron TG responses, in agreement with previous results. ${ }^{[29]}$ Finally, lutein response also correlated with chylomicron vitamin $\mathrm{D}_{3}$ response. These correlations were also significant when considering data for some individual matrices. Considering the existence of low, normal, and high lipid ${ }^{[46]}$ or fat-soluble micronutrient responders, ${ }^{[47]}$ our study also evidenced that the high TG responders are also likely high vitamin $\mathrm{D}_{3} /$ lutein responders. Our study further indicates that high responders for one fat-soluble micronutrient are likely to be high responders for another fat-soluble micronutrients.

Previous data showed that supramolecular organization and physical state of lipids in native and formulated food products can modulate both the digestibility and metabolism of dietary fat. In particular, emulsification in small lipid droplets leads to an enhancement of fat absorption. ${ }^{[48]}$ This was confirmed in our study as the highest TG postprandial response was observed after custard consumption (smallest fat droplets) while the lowest TG postprandial response was observed after biscuit (biggest fat droplets). Indeed, TG response after biscuit consumption was 55\% lower than after custard consumption. This decrease could also be linked to the biscuit matrix as its solid structure would slow the accessibility of the lipid droplets to enzymes. However, none of the model foods had an impact on the time of the maximal postprandial TG blood concentration, which was observed at $3 \mathrm{~h}$. This indicates that the structure of the food matrix neither delayed the accessibility of TG to enzymes during the digestion process, nor fatty acid absorption and secretion into chylomicrons.

Interestingly, such reduction in absorption after the ingestion of the biscuit matrix was also observed for vitamin $D_{3}(-21 \%$ after biscuit compared to sponge cake). This decrease in vitamin $\mathrm{D}_{3}$ absorption may be due to a vectorization of this vitamin in a lipid emulsion displaying large-size fat droplets, which is are less efficiently absorbed. However, the model food structure did not significantly modify the lutein response. This lack of effect can be due to the above-mentioned extremely high interindividual variability regarding lutein responses (ratio between the highest and the lowest responder $=69$ for lutein, while this ratio $=7$ for vitamin $\mathrm{D}_{3}$ ). The difference observed between vitamin $\mathrm{D}_{3}$ and lutein responses may also be related to the fact that the two components display very different chemical structures. Indeed, vitamin $D_{3}$ is a sterol-like molecule while lutein is an oxygenated tetraterpenoid. Such difference can impact the ability of the molecules to transfer to mixed micelles and to be absorbed and secreted by enterocytes.

Both vitamin $\mathrm{D}_{3}$ and lutein maximal blood concentrations were delayed for about $1 \mathrm{~h}$ after biscuit intake compared to other matrices. This result is consistent with a recent study in minipigs aiming at comparing lutein response after pure lutein (i.e., without matrix) or spinach lutein ingestion. This study showed no difference in lutein responses, but the lutein peak was delayed from 2 to $6 \mathrm{~h}$ with spinach, ${ }^{[49]}$ indicating that the food matrix can modulate micronutrient absorption rate.

Additionally, both vitamin $\mathrm{D}_{3}$ and lutein maximal blood concentrations were also delayed for $1 \mathrm{~h}$ compared to TG after biscuit intake ( $4 \mathrm{~h}$ vs $3 \mathrm{~h}$ ). Such differences in maximal postprandial blood concentrations of TG and of vitamin $\mathrm{D}_{3} /$ lutein suggest 
that, compared to other matrices, biscuit induced either i) a delay in intestinal absorption of fat-soluble micronutrients compared to TG, ii) a different mechanism for the incorporation of TG and fat-soluble micronutrients into chylomicrons, or iii) a differential clearance for these compounds in chylomicron remnants. Further investigations are required to validate these assumptions.

Finally, it is worth mentioning that the decrease in TG and vitamin $\mathrm{D}_{3}$ responses observed in this study with some matrices may be balanced by increased TG and vitamin $\mathrm{D}_{3}$ in the chylomicron secretion following the next meal. Indeed, the intestine has the capacity to store some lipid molecules such as cholesterol and vitamin E from one meal and to secrete them during subsequent postprandial periods. ${ }^{[50]}$

In conclusion, we showed that food structure can influence the absorption of fat-soluble (micro)nutrients in humans. In particular, it can lead to modification in amounts of absorbed TG and vitamin $\mathrm{D}_{3}$. Thus, food structure might be a technological lever to optimize the bioefficiency of vitamin $\mathrm{D}_{3}$-supplemented foods in a context of deficient populations. Moreover, this study highlighted that food structure can lead to a delay in both vitamin $\mathrm{D}_{3}$ and lutein postprandial peaks, although the physiopathological consequences of such absorption rate modulation are not yet known. Overall, this study confirms the importance of further investigation to better understand the impact of matrix characteristics on food nutritional quality. This may be of particular interest to develop functional foods for population subgroups deficient or sub-deficient in fat-soluble vitamins, such as the elderly.

\section{Supporting Information}

Supporting Information is available from the Wiley Online Library or from the author.

\section{Acknowledgements}

B.G. and M.H. contributed equally to this work. This project was funded by a grant from the Institut Carnot Qualiment. The authors are grateful to Dr. Claire Dufour (UMR SQPOV, Avignon, France) for helpful suggestions on the manuscript.

\section{Data Availability Statement}

The data that support the findings of this study are available from the corresponding author upon reasonable request.

\section{Author Contributions}

F.N. initiated the project. B.G., N.M., R.R., I.S.-A., C.B., M.-A.P., C.C.-V., F.N., and E.R. designed the clinical study. M.H. and F.N. designed the model foods. N.M., R.R., I.S.-A., and C.B. conducted the clinical study. E.R. and C.H. performed vitamin D analysis. B.G. performed lutein and triglyceride analysis. B.G. and B.P. did the statistical analyses. E.R. and B.G. interpreted the data with F.N. and M.H.; E.R. and B.G. drafted the manuscript; all authors have read and approved the final manuscript; E.R. had primary responsibility for the final content of the manuscript.

\section{Conflict of Interest}

The authors declare no conflict of interest.

\section{Keywords}

carotenoids, clinical trial, cholecalciferol, chylomicrons, bioavailability

Received: March 9, 2020

Revised: September 10, 2020

Published online:

[1] J. Hilger, T. Goerig, P. Weber, B. Hoeft, M. Eggersdorfer, N. C. Carvalho, U. Goldberger, K. Hoffmann, Nutrients 2015, 7, 6938.

[2] B. Roman Vinas, L. Ribas Barba, J. Ngo, M. Gurinovic, R. Novakovic, A. Cavelaars, L. C. de Groot, P. van't Veer, C. Matthys, L. Serra Majem, Ann. Nutr. Metab. 2011, 59, 84.

[3] M. F. Holick, Rev. Endocr. Metab. Disord. 2017, 18, 153.

[4] A. Azzi, S. N. Meydani, M. Meydani, J. M. Zingg, Arch. Biochem. Biophys. 2016, 595, 100.

[5] S. J. Wimalawansa, Ann. N. Y. Acad. Sci. 2011, 1240, E1.

[6] C. Chan, I. Leung, K. W. Lam, M. O. Tso, Curr. Eye Res. 1998, 17, 890.

[7] R. A. Bone, J. T. Landrum, L. M. Friedes, C. M. Gomez, M. D. Kilburn, E. Menendez, I. Vidal, W. Wang, Exp. Eye Res. 1997, 64, 211.

[8] D. M. Snodderly, Am. J. Clin. Nutr. 1995, 62, 1448 S.

[9] J. T. Landrum, R. A. Bone, Arch. Biochem. Biophys. 2001, 385, 28.

[10] A. Junghans, H. Sies, W. Stahl, Arch. Biochem. Biophys. 2001, 391, 160

[11] N. I. Krinsky, J. Nutr. 2002, 132, 540S.

[12] L. M. Rapp, S. S. Maple, J. H. Choi, Invest. Ophthalmol. Visual Sci. $2000,41,1200$

[13] N. K. Scripsema, D. N. Hu, R. B. Rosen, J. Ophthalmol. 2015, 2015, 865179.

[14] N. E. Moran, E. S. Mohn, N. Hason, J. W. Erdman, E. J. Johnson, Adv. Nutr. 2018, 9, 465

[15] E. Reboul, Food Funct. 2015, 6, 356

[16] K. Nyemb, C. Guérin-Dubiard, S. Pézennec, J. Jardin, V. Briard-Bion, C. Cauty, S. M. Rutherfurd, D. Dupont, F. Nau, Food Hydrocolloids 2016, 54, 315.

[17] N. Innocente, M. Biasutti, E. Venir, M. Spaziani, G. Marchesini, J. Dairy Sci. 2009, 92, 1864.

[18] D. Freitas, S. Le Feunteun, Food Chem. 2019, 274, 566.

[19] K. Ogungbenro, L. Aarons, J. Pharmacokinet. Pharmacodyn. 2010, 37, 67.

[20] K. Ogungbenro, L. Aarons, Pharm. Stat. 2010, 9, 255.

[21] G. M. Bornhorst, K. Kostlan, R. P. Singh, J. Food Sci. 2013, 78, E1383.

[22] P. A. Vesilind, Resour. Recovery Conserv. 1980, 5, 275.

[23] L. J. Zhao, Y. Zhou, F. Bu, D. Travers-Gustafson, A. Ye, X. Xu, L. Hamm, D. M. Gorsage, X. Fang, H. W. Deng, R. R. Recker, J. M. Lappe, J. Clin. Endocrinol. Metab. 2012, 97, 2699.

[24] E. Reboul, S. Thap, E. Perrot, M. J. Amiot, D. Lairon, P. Borel, Eur. J. Clin. Nutr. 2007, 61, 1167.

[25] A. Goncalves, S. Roi, M. Nowicki, I. Niot, E. Reboul, Mol. Nutr. Food Res. 2014, 58, 2297

[26] E. G. Bligh, W. J. Dyer, Can. J. Biochem. Physiol. 1959, 37, 911.

[27] B. Gleize, M. Steib, M. Andre, E. Reboul, Food Chem. 2012, 134, 2560.

[28] C. Desmarchelier, P. Borel, A. Goncalves, R. Kopec, M. Nowicki, S. Morange, N. Lesavre, H. Portugal, E. Reboul, J. Nutr. 2016, 146, 2421.

[29] P. Borel, C. Desmarchelier, M. Nowicki, R. Bott, S. Morange, N. Lesavre, Am. J. Clin. Nutr. 2014, 100, 168.

[30] E. Reboul, S. Thap, F. Tourniaire, M. Andre, C. Juhel, S. Morange, M. J. Amiot, D. Lairon, P. Borel, Br. J. Nutr. 2007, 97, 440.

[31] E. J. Johnson, S. D. Krasinski, R. M. Russell, Am. J. Clin. Nutr. 1992, 56, 911.

[32] C. Couillard, N. Bergeron, D. Prud'homme, J. Bergeron, A. Tremblay, C. Bouchard, P. Mauriege, J. P. Despres, Arterioscler., Thromb., Vasc. Biol. 1999, 19, 2448 
[33] P. C. Mashurabad, R. Palika, Y. W. Jyrwa, K. Bhaskarachary, R. Pullakhandam, J. Food Sci. Technol. 2017, 54, 333.

[34] K. H. van het Hof, L. B. Tijburg, K. Pietrzik, J. A. Weststrate, Br. J. Nutr. 1999, 82, 203.

[35] P. Borel, D. Caillaud, N. J. Cano, Crit. Rev. Food Sci. Nutr. 2015, 55, 1193.

[36] D. Wagner, G. Sidhom, S. J. Whiting, D. Rousseau, R. Vieth, J. Nutr. 2008, 138, 1365

[37] R. J. Keegan, Z. Lu, J. M. Bogusz, J. E. Williams, M. F. Holick, Dermatoendocrinol. 2013, 5, 165.

[38] B. J. Marriage, J. A. Williams, Y. S. Choe, K. C. Maki, M. Vurma, S. J. DeMichele, Br. J. Nutr. 2017, 118, 813.

[39] P. M. Clifton, M. Noakes, D. Ross, A. Fassoulakis, M. Cehun, P. Nestel, J. Lipid Res. 2004, 45, 1493.

[40] Y. Cohen, M. Levi, U. Lesmes, M. Margier, E. Reboul, Y. D. Livney, Food Funct. 2017, 8, 2133.

[41] J. K. Aschoff, C. L. Rolke, N. Breusing, A. Bosy-Westphal, J. Hogel, R. Carle, R. M. Schweiggert, Mol. Nutr. Food Res. 2015, 59, 1896.

[42] J. J. M. Castenmiller, C. E. West, J. P. H. Linssen, K. H. van het Hof, A. G. J. Voragen, J. Nutr. 1999, 129, 349.
[43] H. S. Kroop, W. B. Long, A. Alavi, J. R. Hansell, Gastroenterology 1979, 77, 997.

[44] C. Dubois, G. Beaumier, C. Juhel, M. Armand, H. Portugal, A. M. Pauli, P. Borel, C. Latge, D. Lairon, Am. J. Clin. Nutr. 1998, 67, 31.

[45] C. Desmarchelier, J. C. Martin, R. Planells, M. Gastaldi, M. Nowicki, A. Goncalves, R. Valero, D. Lairon, P. Borel, J. Clin. Endocrinol. Metab. 2014, 99, E484.

[46] J. Schrezenmeir, P. Weber, R. Probst, H. K. Biesalski, C. Luley, W. Prellwitz, U. Krause, J. Beyer, Ann. Nutr. Metab. 1992, 36, 186.

[47] P. Borel, P. Grolier, N. Mekki, Y. Boirie, Y. Rochette, B. Le Roy, M. C. Alexandre-Gouabau, D. Lairon, V. Azais-Braesco, J. Lipid Res. 1998, 39, 2250.

[48] M. C. Michalski, C. Genot, C. Gayet, C. Lopez, F. Fine, F. Joffre, J. L. Vendeuvre, J. Bouvier, J. M. Chardigny, K. Raynal-Ljutovac, Steering Committee of RMT LISTRAL, Prog. Lipid Res. 2013, 52, 354.

[49] M. Margier, C. Buffiere, P. Goupy, D. Remond, C. Halimi, C. Caris, P. Borel, E. Reboul, Mol. Nutr. Food Res. 62, 2018, 1800185.

[50] E. Reboul, Am. J. Clin. Nutr. 2019, 110, 1045. 